\title{
Identificação molecular de espécies de vírus e reação fenotípica de famílias de melancia a um isolado do vírus da mancha anelar do mamoeiro, estirpe melancia (Pappaya ringspot virus - strain watermelon - PRSV-W)
}

\author{
Ildon Rodrigues do Nascimento ${ }^{1}$, Luniara Bastos dos Santos ${ }^{1}$, Antônia dos Reis Figueira ${ }^{2}$, \\ Gil Rodrigues dos Santos ${ }^{1}$, Raimundo Wagner de Souza Aguiar ${ }^{1}$, Wilson Roberto Maluf ${ }^{2}$ e \\ Gilberto Iris Souza de Oliveira ${ }^{1}$
}

${ }^{1}$ Departamento de Agronomia - Mestrado em Produção Vegetal; Universidade Federal do Tocantins; 77402-970; Gurupi - TO - Brasil. ${ }^{2}$ Departamento de Fitotecnia e Fitosanidade; Universidade Federal de Lavras; 37.200-000.

\begin{abstract}
The curcubit, including watermelon, are affected by various diseases caused by viruses. In Brazil, has predominated species of the Potyvirus. This study aimed was molecular identification of the virus species from four producer regions of watermelon the state of Tocantins and test through artificial inoculation, the reaction of the progenies selected for phenotypic resistance to one of those characterized as isolated from PRSV-W. Of the nine isolates tested, six presented bands for PRSV-W. One of the isolates presented bands for PRSV-W and SqMV which can be a mixed infection. In phenotypic analysis, access PI 595201 showed a high level of resistance. The progenies had different behavior, and was identify within each progenies plants with similar resistance to the resistant parent.
\end{abstract}

Key words: Citrullus lanatus (Thunb.) Matsum.\& Nakai; selection, viruses, genetic resistance

\section{INTRODUÇÃO}

A melancia (Citrulluslanatus (Thunb.) Matsum \&Nakai) pertence à família Cucurbitaceae e tem origem no continente africano. Atualmente, é cultivada em todos os continentes e seus frutos são apreciados por consumidores de todo o mundo, principalmente nas regiões tropicais (Santos et al., 2005).

Segundo Vieira et al. (2005) as cucurbitáceas, estão sujeitas a várias doenças causadas por vírus que podem reduzir substancialmente a sua produtividade, tanto quantitativa como qualitativamente. No caso da melancia, já foram relatados várias espécies de vírus em plantios comerciais no Brasil, predominando as espécies do gênero Potyvirus.

No Estado de São Paulo, avaliações sobre a ocorrência de viroses em melancia indicaram a predomínio de PRSV-W (Pappaya ring spot vírus - estirpe melancia) $(68,7 \%)$, seguido pelo ZYMV (Zucchini yellow mosaic virus) $(18,7 \%)$; WMV (Watermelon mosaic vírus) (6,6\%); CMV (Cucumber mosaic vírus) (4,2\%); e ZLCP
(Zucchini lethal chlorosis vírus) $(3,1 \%)$ (Yuki et al., 2000). Em áreas de cultivo de melancia no submédio São Francisco, também foi constatada a predominância do PRSV-W (49,1\%), seguido pelo WMV (13\%) e CMV (1,9\%) (Lima et al., 1999). No estado do Maranhão, em amostras coletadas em campos de melancia, foram identificados apenas o PRSV-W (60\%) e o WMV $(26,7 \%)$ (Moura et al., 2001). No estado do Tocantins, há apenas um estudo em uma região produtora de olerícolas onde, na cultura da melancia, pôde ser observada a presença apenas de PRSV-W (Lima Neto et al., 2006).

Apesar da importância da cultura da melancia no estado do Tocantins, são poucas as informação disponível sobre a ocorrência de espécie de vírus e seus efeitos sobre o rendimento.

Em condições tropicais, o PRSV-W é tido como fator limitante para a produção de diversas cucurbitáceas, principalmente quando a infecção ocorre no início do ciclo (Bedendo, 1995), provocando sintomas que são caracterizados pela presença de mosqueado, mosaico, clorose, bolhas,

Author for correspondence: ildon@uft.edu.br 
necrose, deformação foliar e de frutos, podendo ocorrer também na forma latente (Beserra Júnior et al., 2006).

O baixo nível de resistência ou tolerância da maioria das cultivares disponíveis e a baixa eficiência dos inseticidas diminui a eficiência do controle químico (Yuki, 1990; Vieira et al., 2005). No Nordeste brasileiro, várias trabalhos de pesquisa vêm sendo conduzidos com acessos locais de melancia como fontes de resistência a viroses (Araújo, 1989; Oliveira et al., 2002; Silveira, 2005; Vieira et al., 2005).

Vieira et al. (2010) em um estudo realizado com três isolados virais de PRSV-W provenientes de diferentes estados em genótipos de melancia, relata que o desenvolvimento de cultivares com resistência ao PRSV-W, deve ser realizado com isolados de vírus provenientes das regiões onde serão recomendados essas cultivares.

De um total de 1.650 acessos africanos de melancia avaliados pelo United States Department of Agriculture (USDA), três acessos da África do Sul (PI 244017, PI 244018 e PI 244019), três acessos do Zimbábue (PI 482342, PI 482318 e PI 482379), um acesso de Botswana (PI 485583) e um acesso da Nigéria (PI 595203) foram reportados como resistentes (Guner e Wehner, 2008). Nos acessos PI 244017, PI 244019 e PI 485583 o controle da resistência ao PRSV-W foi relatado como sendo controlado por um gene recessivo. Em teste de alelismo foi verificado que a resistência nesses três acessos é devido ao mesmo gene, denominado de prv (Guner e Wehner, 2008).

O United States Department of Agriculture (USDA) disponibilizou o acesso de melancia PI 595201 (Citrullus lanatus var. lanatus) proveniente da Nigéria como sendo resistentes ao WMV (Guner e Wehner, 2008). Entretanto, em trabalho de avaliação da resistência, o acesso PI 595201 foi resistente a isolados de WMV e PRSVW provenientes de Minas Gerais (Bezerra Júnior et al., 2006).

$\mathrm{O}$ objetivo desse trabalho foi efetuar a identificação molecular de espécies de vírus provenientes de quatro regiões produtoras de melancia do estado do Tocantins e verificar através da inoculação artificial, a reação fenotípica de famílias selecionadas para resistência a um desses isolado caracterizado como sendo de PRSV-W.

\section{MATERIAIS E MÉTODOS}

\section{Identificação molecular dos isolados virais}

Foram coletadas plantas com sintomas visuais de viroses em lavouras comerciais de melancia em quatro cidades do estado do Tocantins, sendo: um isolado de Formoso do Araguaia - FA; três isolados de Gurupi - GU; dois isolados de Porto Nacional - PN; e três isolados da Lagoa Confusão - LC. Foram coletadas folhas com sintomas característico de virose que foram acondicionadas em caixas térmicas contendo gelo e levadas para a Universidade Federal do Tocantins.

Os isolados coletados foram inoculados $\mathrm{e}$ mantidos em plantas de abóbora cv. Caserta (Cucurbita pepo). Na inoculação, folhas de cada isolado foram maceradas com adição de tampão fosfato potássio $\left(\mathrm{K}_{2} \mathrm{HPO}_{4}\right) 0,01 \mathrm{M}, \mathrm{pH} 7,0$ e $0,1 \%$ de sulfito de sódio $\left(\mathrm{Na}_{2} \mathrm{SO}_{3}\right)$. A inoculação foi realizada por fricção da suspensão viral sobre as folhas cotiledonares, previamente polvilhadas com o abrasivo carborundum, 400 mesh. Após a inoculação, retirou-se, via lavagem, o excesso de abrasivo. Essas plantas foram mantidas em casade-vegetação com telado a prova de afídeos.

Folhas jovens de plantas de abóbora cv. Caserta com sintomas severos de virose de cada isolado foram identificadas, congeladas e levadas para o Laboratório de Virologia Vegetal da Universidade Federal de Lavras. Os nove isolados virais foram novamente inoculados em plantas de abóbora cv. Caserta e mantidos em casa-de-vegetação nas dependências do Departamento de Fitopatologia da UFLA, Setor de Virologia Vegetal. Quando estas apresentaram sintomas típicos de virose, foram coletadas folhas para a identificação da espécie viral via reação molecular.

A extração de RNA viral de cada isolado foi feita pela metodologia Trizol modificada. De cada um dos 9 isolados foram pesadas 0,4 gramas de tecido foliar das plantas e de uma planta sadia (controle negativo) separadamente, totalizando dez amostras. Isoladamente, cada amostra foi macerada em nitrogênio líquido em cadinhos devidamente tratados com dietilpirocarbonato (DEPC), bem como também todo o material de manuseio das amostras para que não ocorresse contaminação com RNA's. Em seguida, em cada macerado foi adicionado $5 \mathrm{ml}$ de Trizol e posteriormente foram distribuídas em 4 tubos e levado para banho-maria por 5 minutos a $60^{\circ} \mathrm{C}$, seguido de agitação por 10 segundos. Para que ocorresse a separação das fases as amostras foram centrifugadas a 12.000 RPM por 10 minutos a 
$4^{\circ} \mathrm{C}$. No sobrenadante foi acrescentado $300 \mu \mathrm{L}$ de clorofórmio isoamílico e levados para agitação. Em seguida foi feita nova centrifugação a 12.000 RPM por 10 minutos a $4^{\circ} \mathrm{C}$.

O RNA total foi precipitado adicionando-se isopropanol $100 \%$ gelado e citrato de sódio 1,2 M na mesma proporção. A suspensão foi centrifugada a $12.000 \mathrm{RPM}$ por 10 minutos a $4^{\circ} \mathrm{C}$. Em seguida, descartou-se o sobrenadante, obtendo o pelet de RNA que foi lavado com $300 \mu \mathrm{L}$ de etanol $70 \%$ e preparado com água tratada com dietilpirocarbonato (DEPC) e centrifugando a 12.000 RPM por 10 minutos. O etanol foi descartado e o precipitado foi seco em capela. Em seguida, este foi dissolvido em $30 \mu \mathrm{L}$ de água Milli-Q estéril tratada com DEPC.

A identificação dos isolados virais foi feita com três primers específicos, sendo dois para Potyvirus [WMV (Watermelon mosaic virus), PRSV-W (Papaya ring spot virus)] e um para um Comovirus [SqMV (Squash mosaic virus)]. Sendo eles: PRSV-W-F-9266: 5'GCTGTGGATGCTGGTCTGA3' Foward; PRSV-W-R-10062:

5'TTCCACTGTGTGTCTCTCC Reverse; WMVF- 8927: 5'CAGTGTCTCTGCAA TCAGGA3' Foward; WMV-R - 9736: 5'CCCTTGCAGTGTGCCTCTCAG Reward; SqMV2501-F: 5' TTTGACGGCATGGTC 3' Foward; SqMV3323-R: 5' GGA AAGAAGCCACAAC 3' Reward.

Para cada reação de transcrição reversa do RNA viral foi utilizado $5 \mu \mathrm{l}$ de RNA total na

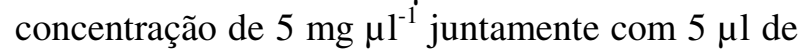
tampão para transcrição reversa (M.MLV 5x), $1 \mu 1$ de DTT, $2 \mu 1$ de dNTP's a $10 \mathrm{mM}, 1 \mu \mathrm{lde}$ cada par de primer $(0,1 \mathrm{mg} / \mu \mathrm{l}), 0,8 \mu \mathrm{l}$ da enzima MLV RT e 5,2 $\mu$ l de água mili-Q tratada com DEPC, totalizando um volume final de $20 \mu 1$.

A amplificação do cDNA ocorreu nas seguintes condições: $95^{\circ} \mathrm{C}$ por 2 minutos, 35 ciclos com desnaturação da fita dupla a $95^{\circ} \mathrm{C}$ por 45 minutos, anelamento do primer de $51^{\circ} \mathrm{C}(\mathrm{PRSV}-\mathrm{W}), 50{ }^{\circ} \mathrm{C}$ (SqMV) e $54^{\circ} \mathrm{C}$ (WMV) e extensão a $72^{\circ} \mathrm{C}$ por 1 minutos. Em seguida foi mantido a temperatura de $72^{\circ} \mathrm{C}$ por cinco minutos. Após a amplificação os fragmentos foram visualizados em gel de agarose a $0,7 \%$ e tampão $0,5 \times$ TE e corados com Brometo de Etídio.

Depois da identificação dos isolados virais, amostras foliares foram coletadas separadamente, congeladas e trazidas para a Universidade Federal do Tocantins e re-inoculadas em plantas de abóbora cv. Caserta.

\section{Ensaio de avaliação fenotípica da reação de} famílias de melancia a um isolado de PRSV-W

$O$ ensaio de avaliação da reação fenotípica de famílias de melancia a um isolado de PRSV-W foi conduzido na área experimental da Universidade Federal do Tocantins - UFT, Campus Universitário de Gurupi, localizado na latitude de $11^{\circ} 43^{\prime} 45^{\prime \prime}$ longitude 49 $04^{\circ} 07^{\prime \prime}$.

$\mathrm{O}$ delineamento experimental utilizado foi $\mathrm{o}$ inteiramente casualizado com quatro repetições. Cada parcela foi formada por cinco copos descartáveis de $720 \mathrm{ml}$ contendo substrato na proporção de duas partes de substrato comercial, uma parte de areia, uma parte de esterco de bovino curtido e uma parte de casca de arroz carbonizada. Utilizou-se uma planta por copo.

Os tratamentos utilizados foram: 23 famílias obtidas de retrocruzamentos do acesso PI 595201 (Genitor nãorecorrente) com a cultivar Crimson Sweet (Genitor recorrente), selecionadas para resistência a PRSV-W e/ou WMV; uma cultivar comercial do tipo Crimson Sweet (padrão de suscetibilidade ao PRSV-W) e o acesso de melancia PI 595201 (utilizado como padrão de resistência), totalizando 25 tratamentos, que foram assim identificados [1-WMX-001G-09-04-5807pl\#07; 2-WMX-001G-09-04-58-07pl\#08; 3WMX-001G-09-04-58-07pl\#14; 4-WMX-001G09-04-03-03pl\#05; 5-WMX-001G-09-04-0303pl\#06; 6-WMX-001G-09-04-03-03pl\#11; 7WMX-001G-09-04-03-03pl\#12; 8-WMX-001G09-04-03-03pl\#13; 9-WMX-001G-09-04-0303pl\#18; 10-WMX-001G-09-04-03-03pl\#21; 11WMX-001G-09-04-03-03pl\#22; 12-WMX-001G14-02-55-01pl\#01; 13-WMX-001G-14-02-5501pl\#03; 14-WMX-001G-14-02-55-01pl\#04; 15WMX-001G-14-02-55-01pl\#05; 16-WMX-001G14-02-55-01pl\#07; 17-WMX-001G-14-02-5501pl\#08; 18-WMX-001G-14-02-55-01pl\#09; 19WMX-001G-14-02-55-01pl\#10; 20-WMX-001G14-02-55-01pl\#11; 21-WMX-001G-14-02-5501pl\#12; 22-WMX-001G-14-02-55-01pl\#13; 23WMX-001G-14-02-55-01pl\#15; 24-Crimson Sweet); 25-PI595201].

Foi utilizado o isolado PN-2 identificado como sendo de PRSV-W, mantido em plantas de abóbora cv. Caserta. Para avaliação fenotípica foram feitas duas inoculações artificiais conforme descrito anteriormente. A primeira 10 dias após o plantio e a segunda, sete dias após a primeira.

As avaliações foram realizadas visualmente aos 40 e 50 dias após o plantio (DAP) por dois avaliadores através de uma escala de notas descrita 
por Oliveira et al (2003), em que: 1 - Folhas sem sintomas; 2 - Poucas folhas com leve mosaico nos bordos; 3 - Maioria das folhas com mosaico; poucas bolhas; 4 - Maioria das folhas com mosaico; muitas bolhas e/ou folhas com leves deformações e 5 - Mosaico intenso e folhas com deformações severas. Em cada tratamento as plantas foram avaliadas individualmente.

Todas as plantas foram avaliadas a cada dois dias, porém foi utilizado para seleção as avaliações realizadas aos 40 e 50 dias após o plantio (DAP). As famílias que não apresentaram sintomas, após esse período foram selecionadas e transplantadas para o campo visando a obtenção de sementes endogâmica.

\section{RESULTADOS E DISCUSSÃO}

\section{Identificação molecular dos isolados virais}

$\mathrm{O}$ isolado proveniente de Formoso do Araguaia e o isolado coletado de uma planta de abóbora cv. Caserta (Cucurbita pepo) foram os únicos que não apresentaram banda características para nenhum dos primers utilizados. Dos nove isolados, seis apresentaram bandas para PRSV-W (Figura 1). Os resultados evidência que também no estado do Tocantins o PRSV-W é aparentemente a virose mais frequiente em curcubitáceas. Em trabalho semelhante realizado em Roraima, em 44,4\% das plantas de curcubitáceas coletadas com sintomas de virose, foram caracterizadas como sendo afetado por PRSV-W (Halfeld-Vieira, 2004).

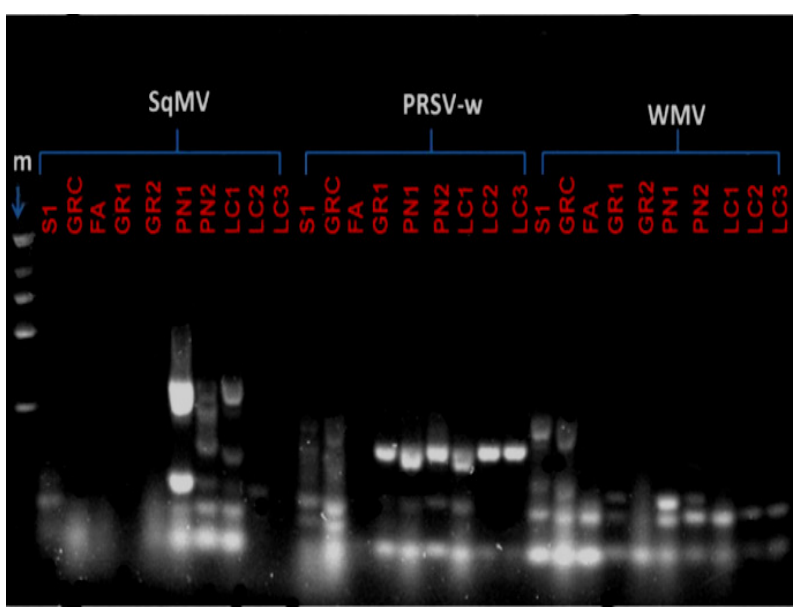

Figura 1- Padrão de bandas em gel de agarose a 0,7\% de isolados de vírus coletados em cucurbitáceas do estado do Tocantins para primer's de SqMV - Squash mosaic virus; PRSV-W - Pappaya ring spot vírus estirpe melancia) WMV - Watermelon mosaic vírus. M : Ladder 100pb; S1: Controle sem sintoma; GRC isolado de Gurupi-TO (coletado em abóbora cv. Caserta); FA - isolado de Formoso do Araguaia - TO (coletado em melancia); GR-1 e GR-2: isolados de Gurupi - TO (coletado em melancia); PN-1 e PN-2 isolado proveniente de Porto Nacional - TO (coletado em melancia); LC-1; LC-2 e LC-3: isolado de Lagoa da Confusão - TO (coletado em melancia).

Bandas que caracterizam a presença de WMV não foram observadas em nenhum dos isolados. Por outro lado, no isolado PN1 além de bandas para PRSV-W foi amplificado também uma banda para o SqM-V, o que pode ser uma infecção mista (Figura 1). Infecções mistas com espécies de vírus de famílias diferentes já foram também reportadas em estudo realizados em outros estados brasileiros (Lima e Vieira, 1992; Yuki et al., 2000).

Lima e Vieira (1992) constataram sintomas de mosaico severo e necrose sistêmica em plantas de melancia resultantes de infecção simultânea de SqMV e PRSV-W em campos com cultivo irrigado de melancia no estado do Piauí.

O PRSV-W encontra-se distribuído mundialmente e é de grande importância econômica onde as cucurbitáceas são cultivadas (Purcifull et al., 1984). Em várias regiões do Brasil, os níveis de incidência dessa virose afetando a melancia já foram estimados.

Em campos irrigados de melão e melancia no Submédio São Francisco na década de 1990 e entre 2005 e 2007, em amostras de cucurbitáceas com sintomas de viroses, foi observado $o$ predominínio de PRSV-W (Lima et al., 1999; Silveira et al., 2009).

Em levantamento realizado na região Norte, o PRSV-W foi o vírus predominantes nas amostras avaliadas por ELISA (Moura et al., 2001; HalfeldVieira et al., 2004), o que corrobora com os resultados aqui apresentados.

A variabilidade genética dos isolados de potyvirus de uma região com os seus hospedeiros locais é grande, por isso uma mesma fonte de resistência, dependendo do seu background pode variar o padrão de fenotípico de sintomas apresentados para diferentes isolados. Este fato deve ser considerado na avaliação de genótipos para resistência a viroses, sendo preferível que os isolados utilizados para seleção em condições controladas sejam provenientes da região onde os genótipos serão utilizados, evitando que a seleção ocorra envolvendo estirpe diferente daquela que se pretende controlar (Silveira et al., 2005).

A não detecção do WMV nas amostras avaliadas pode ser explicada por uma possível inibição ou interferência na sua transmissão pela presença de 
outros vírus. Interferência na transferência de potyvirus já foi relatado por Pinto (2003) para isolados de PRSV-W e ZYMV na transmissão do CMV. Os isolados onde não foram identificado bandas para os primer's utilizados podem ser isolados de vírus para o qual não foi utilizado primer's específicos ou então as plantas estavam apresentando anomalias de natureza diversas das infecções por vírus (Yuki et al., 1999).

Ensaio de avaliação fenotípica da reação de famílias de melancia a um isolado de PRSV-W.

As notas para reação fenotípica estão na Tabela 1. A testemunha utilizada como padrão de suscetibilidade, a cultivar Crimson Sweet, apresentando padrão de sintoma característico de PRSV-W, o que comprova a eficiência da inoculação e virulência do isolado. O sintoma que foi mais comum nas plantas suscetíveis dentro de cada família foi a presença de leve mosaico com o sem deformação foliar. A testemunha resistente (PI 595201) apresentou as menores notas, sem a presença de sintomas visuais nas plantas que foram avaliadas aos 40 e 50 (Dias Após o Plantio - DAÍ).

As menores incidências de PRSV-W após as duas épocas de avaliação depois da inoculação foram observadas nas famílias 12; 2 e 22 (Tabela 1). Em algumas famílias foi observado também regressão dos sintomas da virose, comparando as duas épocas de avaliação. Vieira et al. (2010) também observou regressão de sintomas em dois genótipos de melancia para um isolado de PRSV-W proveniente de São Paulo.

As famílias avaliadas foram oriundas de retrocruzamentos utilizando-se como progenitor recorrente uma cultivar de melancia "Crimson Sweet" e como progenitor não recorrente o acesso PI 595201 tido como resistente. Em cada geração de retrocruzamento, essas famílias foram selecionadas para resistência ao WMV e/ou PRSV-W.

Nas famílias com notas inferiores, espera-se uma freqüência maior dos alelos com genes de resistência, tornando assim necessário a obtenção e avaliação dessas famílias a partir de plantas selecionadas, com base em testes de progênies. É necessário, portanto, acompanhar a genealogia das plantas selecionadas sem sintomas, combinando a seleção de outras características de interesse com a seleção e melhoramento para resistência a viroses, até que seja obtida a homozigose para os alelos que controlam a resistência (Silveira et al., 2005).

Tabela 1. Reação de famílias segregantes de melancia após inoculação artificial do vírus da mancha anelar do mamoeiro, estirpe melancia (Pappaya ringspot vírus - strain watermelon PRSV-W) em duas épocas de avaliação (40 e 50 DAP - Dias Após o Plantio). Gurupi-TO, 2010.

\begin{tabular}{ccc}
\hline \multirow{2}{*}{ Genótipos } & \multicolumn{2}{c}{$\begin{array}{c}\text { Reação a inoculação ao } \\
\text { PRSV-W }\end{array}$} \\
\cline { 2 - 3 } & 40 DAP & 50 DAP \\
\hline 1 & $8 / 20$ & $9 / 20$ \\
2 & $6 / 20$ & $8 / 20$ \\
3 & $10 / 20$ & $19 / 20$ \\
4 & $8 / 20$ & $9 / 20$ \\
5 & $9 / 20$ & $10 / 20$ \\
6 & $13 / 20$ & $14 / 20$ \\
7 & $12 / 20$ & $12 / 20$ \\
8 & $9 / 20$ & $10 / 20$ \\
9 & $10 / 20$ & $11 / 20$ \\
10 & $10 / 20$ & $14 / 20$ \\
11 & $16 / 20$ & $15 / 20$ \\
12 & $5 / 20$ & $6 / 20$ \\
13 & $11 / 20$ & $13 / 20$ \\
14 & $10 / 20$ & $10 / 20$ \\
15 & $10 / 20$ & $12 / 20$ \\
16 & $11 / 20$ & $11 / 20$ \\
17 & $8 / 20$ & $9 / 20$ \\
18 & $8 / 20$ & $10 / 20$ \\
19 & $7 / 20$ & $10 / 20$ \\
20 & $8 / 20$ & $8 / 20$ \\
21 & $9 / 20$ & $10 / 20$ \\
22 & $6 / 20$ & $7 / 20$ \\
23 & $7 / 20$ & $9 / 20$ \\
PI595201 & $0 / 20$ & $0 / 20$ \\
Crimson Sweet & $20 / 20$ & $20 / 20$ \\
\hline
\end{tabular}

' - Numerador: Número de plantas com sintomas de vírose após a inoculação artificial; Denominador: Número de plantas inoculadas com o vírus em casa de vegetação. Em que: 1-WMX-001G-09-04-58-07pl\#07; 2WMX-001G-09-04-58-07pl\#08; 3-WMX-001G-09-04-5807pl\#14; 4-WMX-001G-09-04-03-03pl\#05; 5-WMX001G-09-04-03-03pl\#06; 6-WMX-001G-09-04-0303pl\#11; 7-WMX-001G-09-04-03-03pl\#12; 8-WMX001G-09-04-03-03pl\#13; 9-WMX-001G-09-04-0303pl\#18; 10-WMX-001G-09-04-03-03pl\#21; 11-WMX001G-09-04-03-03pl\#22; 12-WMX-001G-14-02-5501pl\#01; 13-WMX-001G-14-02-55-01pl\#03; 14-WMX001G-14-02-55-01pl\#04; 15-WMX-001G-14-02-5501pl\#05; 16-WMX-001G-14-02-55-01pl\#07; 17-WMX001G-14-02-55-01pl\#08; 18-WMX-001G-14-02-55- 


01pl\#09; 19-WMX-001G-14-02-55-01pl\#10; 20-WMX-
001G-14-02-55-01pl\#11; $\quad$ 21-WMX-001G-14-02-55-
01pl\#12; 22-WMX-001G-14-02-55-01pl\#13; 23-WMX-
001G-14-02-55-01pl\#15.

A seleção para resistência a viroses no acesso PI 595201 será mais simples se a característica for controlada por apenas um alelo recessivo ou dominante e mais complexa quando o controle da resistência depender de mais de um alelo (Danin-Poleg et al., 1997). Esse padrão de resistência pode variar para uma mesma fonte de resistência, conforme se varia o isolado e as condições ambientais, em especial a temperatura do local de avaliação (Vieira et al., 2010). Azevedo (2001) encontraram resistência a PRSVW do tipo oligogênica no acesso PI 595201 para isolados de Minas Gerais.

Foi observado a presença de lesões necróticas nas folhas que foram inoculadas cerca de 24 horas após a inoculação no acesso PI 595201 e também em algumas famílias. Esses aspectos caracterizam a capacidade de contenção da multiplicação da partícula viral no sítio primário de infecção, característico quando ocorre resposta de hipersensibilidade, um fenômeno que envolve o reconhecimento de elicitores do patógeno e a ativação de vias de transdução de sinais que conduzem às respostas de defesa da planta (Nimchuk et al., 2003). Bezerra Júnior et al. (2006) relatam que a multiplicação e/ou translocação viral do PRSV-W pode ser do tipo célula-a-célula não havendo progressão no nível de sintomas ao longo do tempo.

Considerando os danos causados por viroses em cucurbitáceas e em alguns casos a ineficiência do controle dos vetores, a melhor maneira de conviver com essas doenças é o uso de resistência genética (Silveira et al., 2009). Dessa forma, a exemplo de outras regiões, os programas de melhoramento de cucurbitáceas que buscam o desenvolvimento de híbridos e/ou cultivares resistentes para o cultivo nessa região, devem obrigatoriamente considerar a possibilidade de inserir resistência para mais de uma espécie de vírus.

\section{AGRADECIMENTOS}

Ao Conselho Nacional de Desenvolvimento Científico e Tecnológico - CNPq pela concessão de auxílio financeiro para realização do trabalho.

\section{RESUMO}

As curcubitaceas, incluindo a melancia, estão sujeitas a várias doenças causadas por vírus. No Brasil, tem predominado espécies de Potyvirus. O objetivo do trabalho foi efetuar a identificação molecular de espécies de vírus provenientes de quatro regiões produtoras de melancia do estado do Tocantins e verificar através da inoculação artificial, a reação fenotípica de famílias selecionadas para resistência a um desses isolado caracterizado como sendo de PRSVW. Dos nove isolados utilizados, seis apresentaram bandas para PRSV-W. Um dos isolados apresentou bandas para PRSV-W e SqMV que pode ser uma infecção mista. Na avaliação fenotípica, o acesso PI 595201 apresentou alto nível de resistência. As famílias apresentaram comportamento diferenciado, sendo possível identificar plantas dentro de cada família com resistência semelhante ao genitor resistente.

Palavras-chave: Citrullus lanatus (Thunb.) Matsum.\& Nakai, seleção, viroses, resistência genética

\section{REFERÊNCIAS}

Araújo, J. P.; Dias, R. de C. S.; Queiróz, M. A. de; Pessoa, H. B. S. V. (1989), Avaliação de linhas de melancia visando resistência ao vírus WMV-1. Horticultura Brasileira, 7, p. 41.

Azevedo, S. M. Herança da resistência ao vírus da mancha anelar do mamoeiro-estirpe melancia (PRSV-W) em melancia, Citrullus lanatus (Thunb.) Matsu. \& Nakai. Tese (Doutorado em Agronomia) Universidade Federal de Lavras, 2001.

Bedendo, I. P. (1995), Vírus. In: Bergamin-Filho, A.; Kimati, H.; Amorim, L (Org). Manual de fitopatologia- princípios e conceitos. 3ed. São Paulo: Agronômica Ceres, 2, 137-142.

Beserra Jr, J. E. A; Maluf, W. R.; Figueira, A. R.; Barguil, B. M. (2006), Herança da resistência ao Watermelon mosaic vírus em melancia (Citrullus lanatusL.). Fitopatologia Brasileira, 31, 302-305.

Cordeiro, M. C. R.; SÁ, M. F. G. (1999), Biotecnologia e resistência a patógenos. Biotecnologia ciência \& desenvolvimento, 2, 3439.

Danin-Poleg, Y.; Paris, R. S.; Cohen, S.; Rabinowitch, H. D.; Karchi, Z. (1997), Oligogenic 
inheritance of resistance to Zucchini yellow mosaic virus in melons. Euphytica, 93, 331-337.

Dias, P. R. P. e Rezende, J. A. M. (2000), Premunização da abóbora Tetsukabuto para o controle do mosaico causado pelo Papaya ring spot virus - type $W$. Summa Phytopathologica, 26, 390-398.

Durrant, W. E. e Dong, X. (2004), Systemic acquired resistance. Annual Review of Phytopathology, Palo Alto, 42, 185-209, In: Silva, R. A.; Reis, V. M.; Baldani,J. I., Olivares, F. L. (2008). Defesa de plantas contra o ataque de fitopatógenos. Seropédica: Embrapa Agrobiologia, p. 49.

Guner, N. and Wehner, T. C. (2008), Overview of Potyvirus resistance in watermelon. In: Cucurbitaceae - Proceedings of the IXth EUCARPIA meeting on genetics and breeding of Cucurbitaceae. Disponível em: https://w3.avignon.inra.fr/dspace/ bitstream/2174/245/1/30_39_Wehner.pdf. p.445452.

Halfeld-Vieira, B. A.; Ramos, N. F.; Rabelo Filho, F. A. C.; Gonçalves, M. F. B.; Nechet, K. L.; Pereira, P. R. V. S.; Lima, J. A. A. (2004), Identificação sorológica de espécies de potyvirus em melancia, no estado de Roraima. Fitopatologia Brasileira, 29, 687-689.

Lima Neto, A. F.; Boiteux, L. S.; Costa, P. C.; Alencar, R. A.; Ferreira, F. M.; Silva Neto, I. G.; Reis, A. (2006), Levantamento de doenças em hortaliças cultivadas na região da 'Matinha' (Guaraí, Tocantins). $\quad$ CBO 2006 www.abhorticultura.

Lima, M. F.; Barbosa, L. F.; de Àvila A. C. (1999), Levantamento de viroses na cultura de melancia na região do submédio do vale São Franscisco. Fitopatologia Brasileira, 22: 337.

Lima, J. A. A. e Vieira, A. C. (1992), Distribuição do vírus do mosaico da abobara em municípios cearenses e gama de hospedeiras de um isolado. Fitopatologia Brasileira, 17, 112-114.

Moura, M. C. C. L.; Lima, J. A. A.; Oliveira, V. B.; Gonçalves, M. F. B. (2001), Identificação sorológica de espécie de vírus que infectam cucurbitáceas em áreas produtoras do maranhão. Fitopatologia Brasileira, 26, 90-92.

Nimchuk, Z.; Eulgem, T.; Holt, B. F.; Dangl, J. L. (2003), Recognition and response in the plant immune system. Annu. Rev. Genet. 37, 579-609.

Oliveira, A. C. B.; Maluf, W. R.; Pinto, J. E. B. P.; Azevedo, S. M. (2003), Resistance to Papaya ringspot virus in Cucurbitapepo L. introgressed from a interspecific $C$. pepox $C$. moschata cross. Euphytica, Wageningen, 132, 211-215.

Oliveira, V. B. de; Queiroz, M. A. de; Lima, A. A. (2002), Fontes de resistência em melancia aos principais potyvírus isolados de cucurbitáceas no Nordeste brasileiro. Horticultura Brasileira, 20, 589-592.

Oliveira, A. C. B.; Maluf, W. R.; Pinto, J. E. B. P.; Azevedo, S. M. (2003), Resistance to Papaya ringspot virus in Cucurbita pepo L. introgressed from a interspecific C. pepox C. moschata cross. Euphytica, 132, 211-215.

Pinto, Z. V. Efeito da origem dos isolados do Cucumber mosaic vírus (CMV) e da presença de dois potyvirus na transmissão do CMV para abobrinha de moita por meio de duas espécies de afídeos. Dissertação (Mestrado em Agronomia). ESALQ - Universidade de São Paulo, 2003.

Purcifull, D. E.; Alderz, W. C.; Simone, G. W.; Hiebert, E.; Christie, S. R. (1984), Serological relationships and partial characterization of Zucchini yellow mosaic virus isolated from squash in Florida. Plant Disease, 68, 230-233.

Rezende, J. A. M. Premunização de duas espécies e um híbrido de Cucurbitapara o controle do mosaico causado pelo vírus do mosaico do mamoeiro - estirpe melancia. . Tese (Doutorado em Agronomia) - Escola Superior de Agricultura "Luiz de Queiroz", Universidade de São Paulo. 1996.

Rezende J. A. M.; Pacheco D. A.; Iemma A. F. (1999), Efeitos da premunização da abóbora 'Menina Brasileira' com estirpes fracas do vírus do mosaico do mamoeiro-estirpe melancia. Pesquisa Agropecuária Brasileira, 34, 1481-1489. 
Santos, G. R.; Zambolim, L.; Rezende. J. A. M.; Costa, H. (2005), Manejo integrado de doenças da melancia.Viçosa: p. 62.

Silveira, L. M.; Queiroz, M. A.; Lima, J. A. A.; Negreiros, M. Z.; Ramos, N. F.; Nascimento, A. Q. (2005), Seleção de acessos a progênies de Citrullus spp. Para resistência a três potyvirus. Fitopatologia Brasileira, 30, 394-399.

Silveira, L. M.; Queiroz, M. A.; Lima, J. A. A.; Nascimento, A. K. Q.; Lima Neto, I. S. (2009), Levantamento sorológico de vírus em espécies de cucurbitáceas na região do submédio São Francisco, Brasil. Tropical Plant Pathology, 34, 123-126.

Vieira, J. V.; Avila, A. C.; Pinto, M. N.; Silva, B. M. da; Borges, C. L. (2005), Avaliação da coleção de germoplasma de melancia da Embrapa
Hortaliças para tolerância a viroses. Brasília: Embrapa Hortaliças (Boletim de Pesquisa e Desenvolvimento).

Vieira, J. V.; Ávila, A. C.; Silva, G. O. (2010), Avaliação de genótipos de melancia para resistência ao Papaya ring spot virus, estirpe melancia. Horticultura Brasileira, 28, 7 - 11.

Yuki, V. A.; Rezende, J. A. M.; Kitajima, E. W.; Barroso, P. A. V.; Kuniyuki, H.; Groppo, G. A.; Pavan, M. A. (2000), Occurrence, distribution and elative incidence of viruse infecting cucurbits in the State of São Paulo, Brazil. Plant Disease, 84, 516-520.

Yuki, V. A. Epidemiologia e controle do mosaico (VMM-Me) em abobrinha-de-moita. Tese (Doutorado em Agronomia) Escola Superior de Agricultura "Luiz de Queiroz", Universidade de São Paulo, 1990. 